\title{
OPEN Three-dimensional CBCT based evaluation of the inferior part of the maxillary sinus: Retrospective Study
}

\author{
Jeong-Hyun Lee ${ }^{1}$, Won-Jeong Han² \& Jong-Tae Park ${ }^{1 凶}$
}

The maxillary sinus is the largest of the four paranasal sinuses in humans, and its close proximity to the teeth means that caution is required during dental treatment. In particular, implant surgeries involving the maxillary posterior teeth should include evaluating the inferior part of the maxillary sinus. The purpose of this study is to evaluate the differences by comparing the inferior part of the maxillary sinus based on the nasal cavity floor (NCF) between patients (male 30, female 30) genders through the use of the three-dimensional (3-D) program that can facilitate 3-D visualizations. The present study results obtained from 3-D visualizations using cone beam computed tomography (CBCT) data showed that the inferior part of the maxillary sinus was mostly larger in males than in females. In addition, the utilization of 3-D visualization data was more likely to assure accuracy than when using data obtained by two-dimensional (2-D) imaging. Therefore, 3-D visualizations of the inferior part of the maxillary sinus will contribute to accurate analyses of its anatomical structure during implant surgery and other operations. Further studies utilizing 3-D visualization will yield useful fundamental data and guidelines for future research.

The maxillary sinus is the largest of the four paranasal sinuses in humans, and its close proximity to the teeth means that caution is required during dental treatment ${ }^{1}$. Of them, the inferior part of maxillary sinus is an important anatomical structure considered first in clinical practice. In particular, implant surgeries involving the maxillary posterior teeth should include evaluating the inferior part of the maxillary sinus. Implant surgery involves performing a surgical procedure for a missing tooth ${ }^{2}$. Severe loss of alveolar bone necessitates the use of bone grafting and maxillary sinus floor augmentation procedures for the maxilla ${ }^{3}$. However, maxillary sinus floor augmentation frequently leads to complications such as perforation in the inferior part of the maxillary sinus, excessive bleeding, and hematoma ${ }^{4,5}$. Hence, dental radiographs have been used to analyze the anatomical structure of the inferior part of the maxillary sinus, including to predict the prognosis of implant surgery ${ }^{3,6-12,14-16}$. However, it is difficult to differentiate between the maxillary sinus floor and the Schneiderian membrane on radiographs ${ }^{7}$. Accurate measurements are especially important for surgical treatment, and the use of cone-beam computed tomography (CBCT) for observing the anatomical structure of the inferior part of the maxillary sinus is still in its infancy.

$\mathrm{CBCT}$ allows the assessment of complicated anatomical structures that are difficult to observe on panoramic scans due to the presence of overlapping structures. CBCT has previously been used in the treatment of lesions, trauma, and congenital malformation surgery, but it is now also being widely used in dental clinics ${ }^{3,6-12,14-16}$. Studies have used CBCT in maxillary sinus floor augmentation for measuring the height of the residual bone crest $^{6,8,9}$, the thickness of the lateral maxillary sinus bone wall ${ }^{6,10,11}$, and the angle of the palatal-nasal recess $(\mathrm{PNR})^{3,11}$ in the inferior part of the maxillary sinus. Therefore, the inferior part of maxillary sinus is an anatomically and clinically important structure. Nevertheless, studies reported so far measured CBCT in two-dimensional (2-D) without visualizing it in three-dimensional (3-D) $)^{3,6-12,14-16}$. CBCT does not suffer from panoramic overlap, analyses might not be accurate without utilizing 3-D visualization ${ }^{7}$. Hence, studies utilizing the 3-D visualization capabilities of CBCT are required.

The nasal cavity floor (NCF) is a baseline that is currently considered important in implant surgery. In particular, NCF acts as a criterion for bone implantation to enable implant placement during maxillary sinus floor

\footnotetext{
${ }^{1}$ Department of Oral Anatomy, Dental College Dankook Institute For Future Science and Emerging Convergence, Dan-Kook University, Cheonan 330-714, South Korea. ${ }^{2}$ Department of Dentomaxillofacial Radiology, Dental College, Dan-Kook University, Cheonan 330-714, South Korea. ${ }^{\circledR}$ email: jongta2@dankook.ac.kr
} 


\begin{tabular}{|l|l|}
\hline Parameter & Definition \\
\hline NCF-F & Height of the inferior part of the maxillary sinus, from the floor to the NCF \\
\hline CW & Width of the inferior part of the maxillary sinus from the coronal view \\
\hline SW & Width of the inferior part of the maxillary sinus from the sagittal view \\
\hline V & Volume between the maxillary sinus floor and the NCF \\
\hline PNR angle & Angle of the palatal bone and nasal bone wall \\
\hline
\end{tabular}

Table 1. Parameters of the inferior part of the maxillary sinus. NCF, nasal cavity floor; PNR, palatal-nasal recess.

augmentation ${ }^{17}$. In addition, it is possible to prevent complications such as bleeding, pain, cross-contamination, implant displacement, and sinusitis when maxillary sinus floor augmentation and implant surgery are performed based on $\mathrm{NCF}^{18}$. As such, it is commonly used for implant surgery based on NCF. However, only cross- sectional area of CBCT has been measured in most current studies.

The purpose of this study is to evaluate the differences by comparing the inferior part of the maxillary sinus based on the NCF between patients' genders through the use of the Mimics program that can facilitate 3-D visualizations. In addition, we aimed to determine the accuracy and difference between the measured length in 2-D of previous studies and the measurement conducted via 3-D visualization in this study. Therefore, this study measured the distance between the zygomatic arch to examine the facial width, with an aim to determine the relationship between facial width and the inferior part of the maxillary sinus.

\section{Materials and methods}

Study participants. Among the malocclusion (class I, II, III) patients in their twenties who visited the Orthodontics Department of Dankook University Dental Hospital, CBCT data were obtained from 60(male 30, female 30) adults without missing teeth, asymmetry, or systemic disease from the Oral Maxillofacial Radiology Department. In addition, the G-Power 3.1 (HHU, England) program was used to calculate the number of samples for the study participants.

The study was conducted after IRB (Dankook University Dental Hospital, approval no. DUDH IRB 2015-12022) had been approved. This study is a retrospective analysis of radiological imaging data which were obtained from the completed check-up processes. Thus, an application for waiver of consent was requested and was approved by the institutional review committee of Dankook University Dental Hospital.

Methods. Generation of 3-D images. The CBCT data of the participants were obtained in DICOM format from the images captured by a scanner (Alphard 3030, Asahi, Kyoto, Japan). CBCT scanning was performed with a slice increment of $0.39 \mathrm{~mm}$, slice thickness of $0.39 \mathrm{~mm}$, and a matrix of 512 pixels $\times 512$ pixels. The DI$\mathrm{COM}$ images were used to generate 3-D images of the maxillary sinus using the Mimics 3-D imaging program (version 22.0, Materialise).

Parameters. To analyze the inferior part of the maxillary sinus from both the $\mathrm{X}$ - and $\mathrm{Z}$-axes, it was divided based on the nasal cavity floor (NCF) line according to Kawakami et al. ${ }^{12}$. The coronal view (C-axis) and sagittal view (S-axis) of the inferior part of the maxillary sinus were analyzed as listed in Table 1 (Fig. 1), (Fig. 2), (Fig. 3).

To assess the inferior part of the maxillary sinus in relation to the facial width, the bizygomatic breadth was measured as the maximum linear distance between the zygions on CBCT. On the basis of the result, the patients were divided into two groups ${ }^{13}$ : bizygomatic breadths of $\geq 127$ and $<127 \mathrm{~mm}$. Among the males, 14 patients were included in the $\geq 127$ - $\mathrm{mm}$ group and 16 in the $<127-\mathrm{mm}$ group, while among the females, 17 patients were included in the $\geq 127$ - $\mathrm{mm}$ group and 13 in the $<127$ - $\mathrm{mm}$ group (Table 2), (Fig. 4). In order to ensure the accuracy of the measurements in the present study, two researchers (Lee, Park) recorded the measurements. After comparing their averages, statistical analysis was conducted.

Statistics. The measured parameters were analyzed using the Statistical Package for the Social Sciences (SPSS version 23.0, IBM, New York). Since the number of participants was small, significance was validated using the normality test followed by the Mann-Whitey $U$ test. Post-hoc analysis was conducted at a $95 \%$ confidence interval, and differences in the mean values between males and females were validated. In addition, linear regression analysis was performed to find out whether bizygomatic breadths according to gender had an effect on the inferior portion of the maxillary sinus floor. The threshold for statistical significance was 0.05 .

Ethics approval. The study was conducted after IRB (Dankook University Dental Hospital, approval no. DUDH IRB 2015-12-022) had been approved. This study is a retrospective analysis of radiological imaging data which were obtained from the completed check-up processes. Thus, an application for waiver of consent was requested and was approved by the institutional review committee of Dankook University Dental Hospital.

Related guidelines and regulations. This study was conducted with the methods in accordance with relevant guidelines and regulations. 


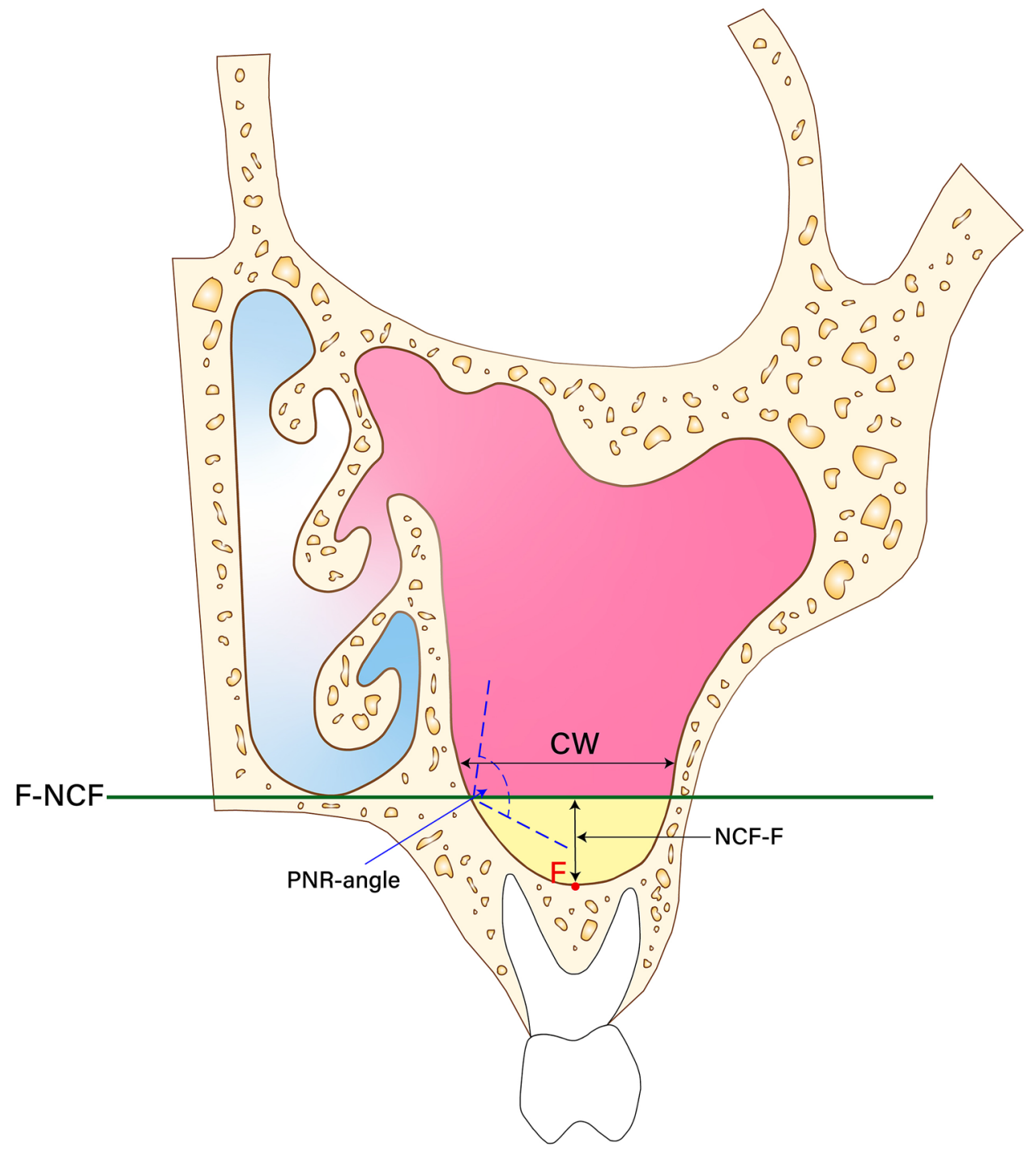

Figure 1. Coronal view. maxillary sinus Floor (F), nasal cavity floor (NCF), height of the inferior part of the maxillary sinus from the F to the NCF (NCF-F), width of the inferior part of the maxillary sinus in the coronal view $(\mathrm{CW})$, Angle of the palatal bone and nasal bone wall (PNR angle).

\section{Results}

The parameters of the inferior part of the maxillary sinus were measured according to sex. The heights of the inferior part of the maxillary sinus from the floor to the NCF (NCF-F values) were $15.06 \mathrm{~mm}$ and $13.30 \mathrm{~mm}$ on the left and right sides respectively in males, and $10.59 \mathrm{~mm}$ and $11.19 \mathrm{~mm}$ in females. NCF-F was significantly larger in males on both sides. The widths of the inferior part of the maxillary sinus from the axial view (CW values) were $24.49 \mathrm{~mm}$ and $24.26 \mathrm{~mm}$ on the left and right sides respectively in males, and $20.65 \mathrm{~mm}$ and $20.31 \mathrm{~mm}$ in females. $\mathrm{CW}$ was significantly larger in males on both sides. The widths of the posterior part of maxillary sinus from the sagittal view (SW values) were $33.64 \mathrm{~mm}$ and $31.34 \mathrm{~mm}$ on the left and right sides respectively in males, and $26.19 \mathrm{~mm}$ and $26.10 \mathrm{~mm}$ in females. SW was also significantly larger in males on both sides ( $\mathrm{p}>0.05)$ (Table 3).

The volumes between the maxillary sinus floor and the NCF (V values) were $27.05 \mathrm{~mm}^{3}$ and $22.55 \mathrm{~mm}^{3}$ on the left and right sides respectively in males, and $17.84 \mathrm{~mm}^{3}$ and $15.04 \mathrm{~mm}^{3}$ in females. $\mathrm{V}$ was significantly larger in males on both sides. The PNR angle was $119.42^{\circ}$ and $119.97^{\circ}$ on the left and right sides respectively in males, and $121.72^{\circ}$ and $120.87^{\circ}$ in females. The PNR angle appeared to be larger in females on both sides, but the difference was not statistically significant (Table 4 ).

With regard to the facial width, the inferior part of the maxillary sinus was compared between the $\geq 127$ and $<127-\mathrm{mm}$ groups in males, between the $\geq 127$ - and $<127-\mathrm{mm}$ groups in females, and between males with $<127 \mathrm{~mm}$ and females with $\geq 127 \mathrm{~mm}$. Regarding the comparison between the $\geq 127$ - and $<127$ - $\mathrm{mm}$ groups in both males and females, the inferior part of the maxillary sinus had larger values for the $\geq 127$-mm group than for the $<127-\mathrm{mm}$ group in general. However, on the right side, males with breadths of $\geq 127 \mathrm{~mm}$ and $<127 \mathrm{~mm}$ had the following values: NCF-F 12.9 and 13.7, CW 23.5 and 25.0, SW 30.9 and 31.7, V 22.0 and 23.1, and PNR angle 123.0 and 123.0 , respectively, indicating that the $<127-\mathrm{mm}$ group had larger values than the $\geq 127-\mathrm{mm}$ 


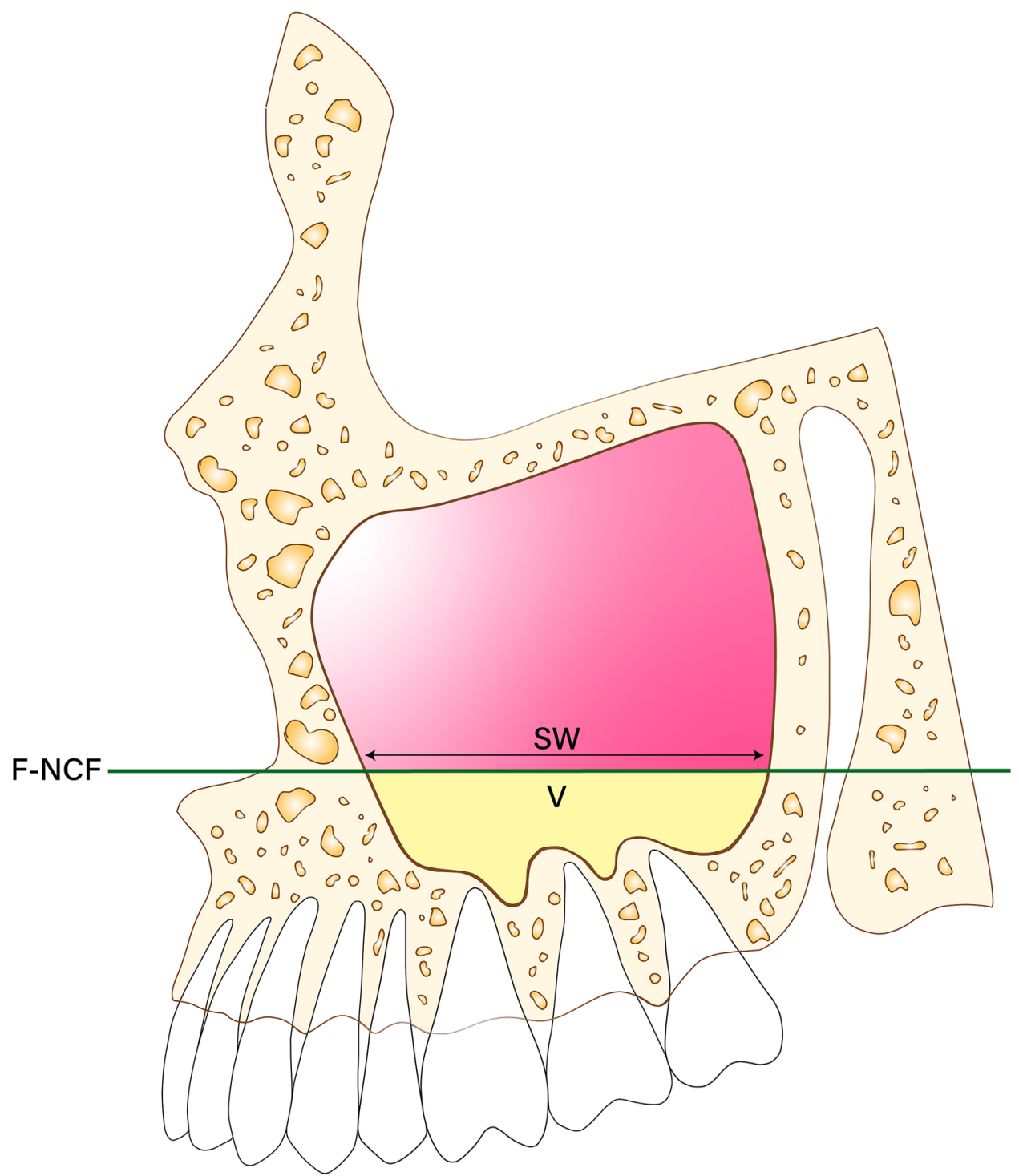

Figure 2. Sagittal view. nasal cavity floor (NCF), width of the inferior part of the maxillary sinus in the sagittal view (SW), volume between the inferior part of the maxillary sinus from the F to the NCF (V).

group. Additionally, females with $\geq 127$ - $\mathrm{mm}$ and $<127$ - $\mathrm{mm}$ breadths had V of 12.5 and 18.4 , respectively, with a larger value for the $<127-\mathrm{mm}$ group. Regarding the comparison between males with $<127$-mm bizygomatic breadth and females with $\geq 127$ - mm bizygomatic breadth, males with $<127$-mm breadth had larger NCF-F, CW, SW, and V, whereas the PNR angle was larger in females with $\geq 127-\mathrm{mm}$ breadth (Table 5).

Simple linear regression was conducted to understand if the distance between the bizygomatic breadths has an influence on the inferior portion of the maxillary sinus floor. The analysis results demonstrated that the regression model is suitable on the right side at $\mathrm{F}=118.252(\mathrm{p}<0.001)$, and a 93\% explanatory power was observed with $\mathrm{R} 2=0.93$. NCF-F showed $\beta=(-0.041), \mathrm{CW} \beta=(0.018), \mathrm{SW} \beta=(0.033), \mathrm{V} \beta=(-0.041)$, and PNR angle $\beta=(-0.173)$. It was found that the distance between the bizygomatic breadths was not statistically significant $(p>0.05)$. However, with regard to sex, $\beta=(-0.173)$ was observed, and the distance between the bizygomatic breadths was statistically significant $(\mathrm{p}<0.01)$. In addition, the $\beta(+)$ values of $\mathrm{CW}, \mathrm{SW}$, and sex all increased as the distance between the bizygomatic breadths increased. On the left side, the regression model was not suitable with $F=0.466(p>0.5)$. A $5 \%$ explanatory power was observed with $R 2=0.050$. NCF-F showed $\beta=(-0.086)$, CW $\beta=(-0.300)$, SW $\beta=(0.072), \mathrm{V} \beta=(-0.028)$, PNR angle $\beta=(-0.114)$, and gender $\beta=(-0.128)$. The distance between the bizygomatic breadths was not statistically significant $(\mathrm{p}>0.05)$. In addition, NCF-F and SW showed $\beta(+)$, and it increased as the distance between the bizygomatic breadths increased (Table 6).

\section{Discussion}

The maxillary sinus has the anatomical shape of a pyramid consisting of four walls (anterior, posterior, superior, and inferior walls) and a floor ${ }^{14}$. The characteristics of the inferior wall can crucially affect dental treatment ${ }^{1}$. In addition, the size and shape of the maxillary sinus vary ${ }^{19}$, and the volume of the maxillary sinus appears to be 

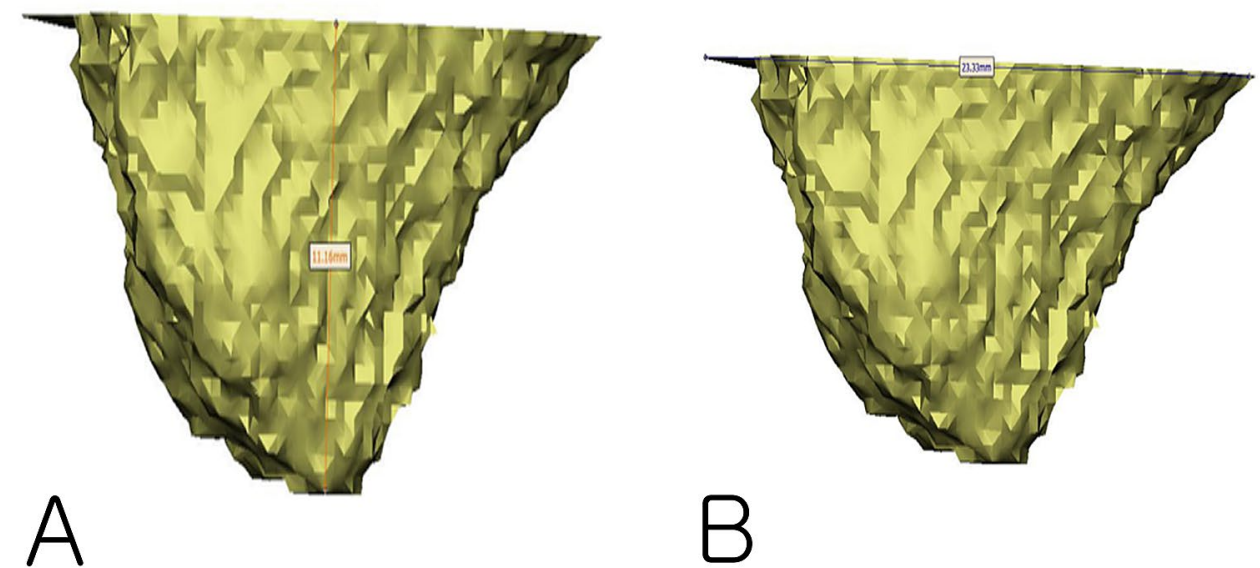

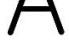
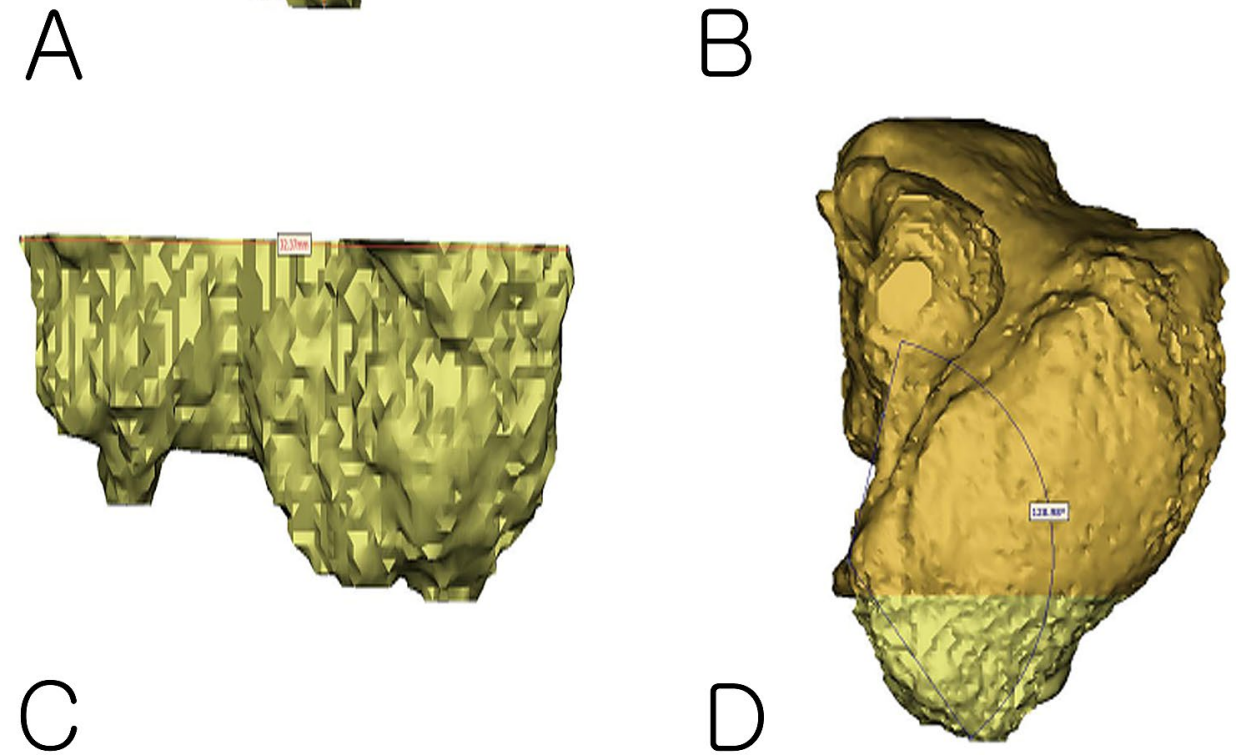

Figure 3. 3D modeling inferior part of the maxillary sinus, (A) height of the inferior part of the maxillary sinus from the F to the NCF, (B) width of the inferior part of the maxillary sinus in the coronal view, $(\mathbf{C})$ width of the inferior part of the maxillary sinus in the sagittal view, (D) Angle of the palatal bone and nasal bone wall.

\begin{tabular}{|l|l|l|}
\hline Measurements & Males & Females \\
\hline$\geq 127$ & 14 & 17 \\
\hline$<127$ & 16 & 13 \\
\hline
\end{tabular}

Table 2. Bizygomatic breadths.

correlated with the interzygomatic buttress distance ${ }^{20}$. However, malocclusion factors and state of the dentition have no influence on the size of maxillary sinus ${ }^{21}$. Thus, while most studies have been conducted on the shape and size of maxillary sinus according to gender ${ }^{3,6-12,14-16}$, studies on the inferior part of the maxillary sinus are insufficient. Furthermore, accurate studies are required since the inferior part of the maxillary sinus is a critical structure that can cause complications during implant surgery. According to the study by Khairnar et al. ${ }^{22}$, it was reported that there were no predicted implant failure and infection symptoms when bone graft was performed on the inferior part of the maxillary sinus based on NCF. Hence, in this study, the inferior part of the maxillary sinus was classified based on the NCF, and this study was conducted to compare differences between genders and the results from the previous studies through 3-D visualization. The main results of this study are discussed below.

In this study, men were shown to be generally larger than women in the NCF-F, CW, SW, and volume categories of the maxillary sinus ( $\mathrm{p}>0.05)$. This was similar to the results of the study by Yoon et al. ${ }^{15}$, which revealed that the total volume of the maxillary sinus was larger in size in men $(18.0 \mathrm{ml})$ than in women $(11.1 \mathrm{ml})$. Consequently, we could confirm that the difference between men and women also appeared in the inferior part of maxillary sinus.

The comparison results between the present study and previous studies are as follows. The length of the FNCF line was measured to determine the height of the inferior part of the maxillary sinus, and the results showed that it was longer in males on both the left and right sides, which is consistent with the results of Cavalcanti 


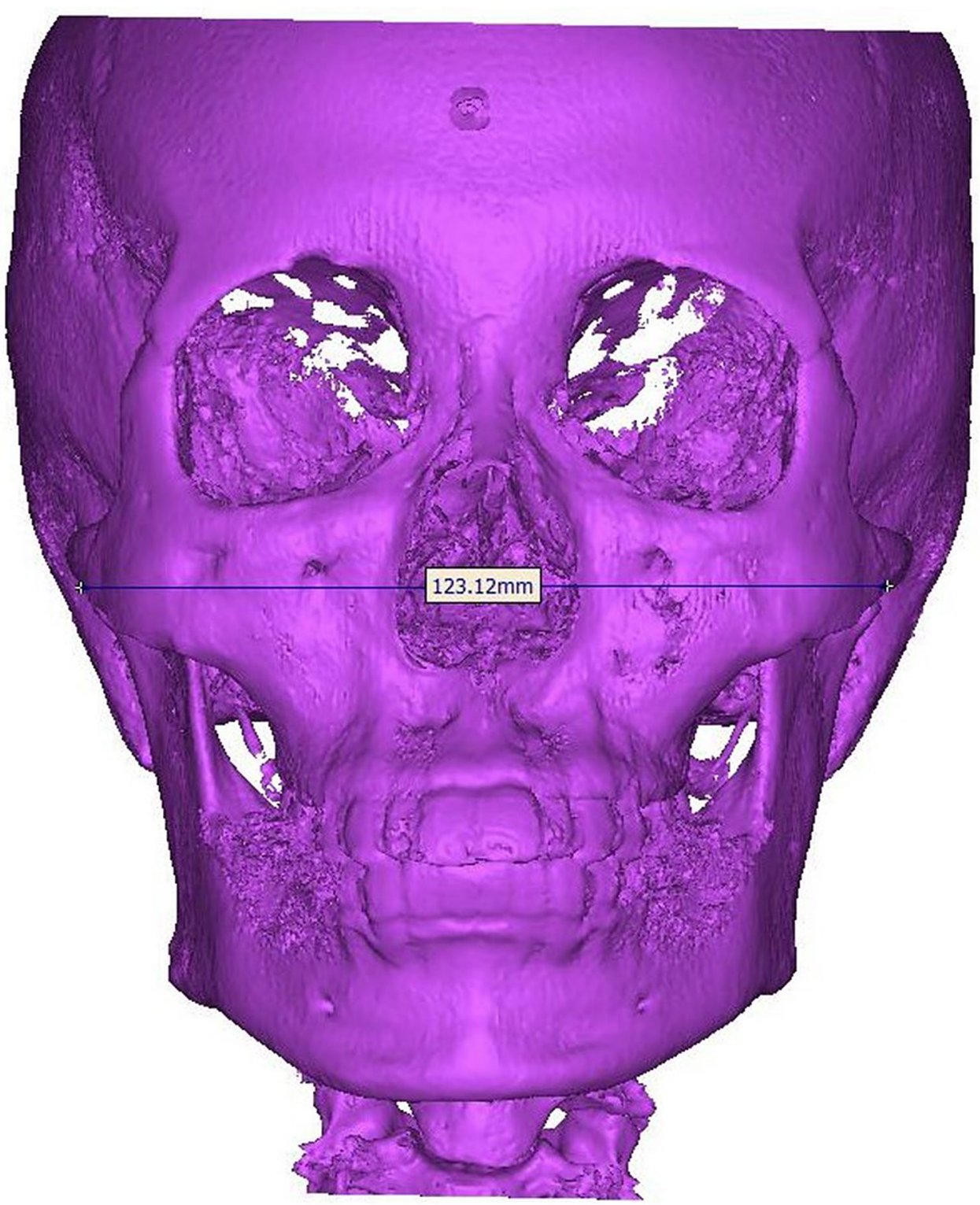

Figure 4. Bizygomatic breadths measurement.

\begin{tabular}{|l|l|l|l|}
\hline Parameter & Males $(\mathbf{n}=\mathbf{3 0})$ & Females $(\mathbf{n}=30)$ & p-value \\
\hline NCF-F $(\mathbf{m m})$ & \multicolumn{5}{|l|}{} \\
\hline Left & $15.06(4.54)$ & $10.59(3.60)$ & $<0.001^{* * *}$ \\
\hline Right & $13.30(3.39)$ & $11.19(5.64)$ & $<0.05^{\star}$ \\
\hline CW $(\mathbf{m m})$ & \multicolumn{5}{|l|}{} \\
\hline Left & $24.49(5.43)$ & $20.65(5.32)$ & $<0.05^{\star}$ \\
\hline Right & $24.26(7.54)$ & $20.31(5.64)$ & $<0.05^{\star}$ \\
\hline SW $(\mathbf{m m})$ & & & \\
\hline Left & $33.64(6.15)$ & $26.19(8.29)$ & $<0.001^{* * *}$ \\
\hline Right & $31.34(7.04)$ & $26.10(7.09)$ & $<0.05^{*}$ \\
\hline
\end{tabular}

Table 3. Differences in NCF-F, CW, and SW according to sex. Data are mean (standard-deviation values). P-value were obtained by Mann-Whitey U test. ${ }^{\star} \mathrm{p}<0.05,{ }^{* * *} \mathrm{p}<0.001$. 


\begin{tabular}{|c|c|c|c|}
\hline Parameter & Males $(n=30)$ & Females $(n=30)$ & p-value \\
\hline \multicolumn{4}{|l|}{$\mathrm{V}\left(\mathrm{mm}^{3}\right)$} \\
\hline Left & $27.05(15.79)$ & $17.84(18.54)$ & $<0.05^{*}$ \\
\hline Right & $22.55(13.37)$ & $15.04(11.72)$ & $<0.05^{*}$ \\
\hline \multicolumn{4}{|c|}{ PNR angle $\left({ }^{\circ}\right)$} \\
\hline Left & $119.42(18.08)$ & $121.72(21.42)$ & 0.690 \\
\hline Right & $119.97(15.97)$ & $120.87(16.20)$ & 0.767 \\
\hline
\end{tabular}

Table 4. Differences in V and PNR angle according to sex. Data are mean (standard-deviation values). P-value were obtained by Mann-Whitey $\mathrm{U}$ test. ${ }^{\star} \mathrm{p}<0.05$.

\begin{tabular}{|c|c|c|c|c|}
\hline \multirow[b]{2}{*}{ Measurements } & \multicolumn{2}{|l|}{ Males } & \multicolumn{2}{|l|}{ Females } \\
\hline & $\geq 127(n=14)$ & $<127(n=16)$ & $\geq 127(n=17)$ & $<127(\mathrm{n}=13)$ \\
\hline \multicolumn{5}{|l|}{ NCF-F (mm) } \\
\hline Left & $15.3(4.0)$ & $14.9(5.1)$ & $10.6(3.0)$ & $10.6(4.4)$ \\
\hline Right & $12.9(3.4)$ & $13.7(3.4)$ & $11.6(5.6)$ & $10.7(5.9)$ \\
\hline \multicolumn{5}{|l|}{$\mathrm{CW}(\mathrm{mm})$} \\
\hline Left & $25.9(6.3)$ & $23.3(4.4)$ & $21.0(4.8)$ & $20.2(6.1)$ \\
\hline Right & $23.5(6.0)$ & $25.0(8.8)$ & $21.3(4.4)$ & $19.0(6.9)$ \\
\hline \multicolumn{5}{|l|}{ SW (mm) } \\
\hline Left & $33.9(6.4)$ & $33.4(6.1)$ & $27.3(7.4)$ & $24.7(9.4)$ \\
\hline Right & $30.9(7.0)$ & $31.7(7.3)$ & $26.9(6.0)$ & $25.0(8.4)$ \\
\hline \multicolumn{5}{|l|}{$\mathrm{V}\left(\mathrm{mm}^{3}\right)$} \\
\hline Left & $28.3(14.7)$ & $26.0(17.1)$ & $19.5(20.8)$ & $15.7(15.6)$ \\
\hline Right & $22.0(13.4)$ & $23.1(13.8)$ & $12.5(9.5)$ & $18.4(13.8)$ \\
\hline \multicolumn{5}{|l|}{ PNR angle $\left({ }^{\circ}\right)$} \\
\hline Left & 115.4(19.6) & $123.0(16.5)$ & $125.1(23.5)$ & $117.3(18.2)$ \\
\hline Right & $123.0(13.2)$ & $117.3(18.1)$ & $122.3(19.1)$ & 121.1(13.6) \\
\hline
\end{tabular}

Table 5. Differences in Inferior part of the maxillary sinus according to bizygomatic breadth. Data are mean (standard-deviation values). P-value were obtained by Mann-Whitey $\mathrm{U}$ test.

\begin{tabular}{|c|c|c|c|c|c|c|}
\hline Measurements & B & SE & $\beta$ & $t(p)$ & $F(p)$ & $R^{2}$ \\
\hline \multicolumn{7}{|l|}{ Right } \\
\hline Constant & -51.283 & 40.125 & & -1.278 & \multirow{7}{*}{118.252} & \multirow{7}{*}{0.93} \\
\hline NCF-F (mm) & -0.198 & 0.433 & -0.041 & -0.458 & & \\
\hline $\mathrm{CW}(\mathrm{mm})$ & 0.068 & 0.199 & 0.018 & 0.342 & & \\
\hline $\mathrm{SW}(\mathrm{mm})$ & 0.160 & 0.401 & 0.033 & 0.400 & & \\
\hline $\mathrm{V}\left(\mathrm{mm}^{3}\right)$ & -0.118 & 0.217 & -0.041 & -0.544 & & \\
\hline PNR angle $\left({ }^{\circ}\right)$ & -0.126 & 0.142 & -0.173 & -0.884 & & \\
\hline Sex & 66.517 & 21.045 & $0.824^{* *}$ & $3.161^{\star *}$ & & \\
\hline \multicolumn{7}{|l|}{ Left } \\
\hline Constant & 2.397 & 0.750 & & 3.194 & \multirow{7}{*}{0.466} & \multirow{7}{*}{0.050} \\
\hline NCF-F (mm) & 0.009 & 0.023 & 0.086 & 0.411 & & \\
\hline $\mathrm{CW}(\mathrm{mm})$ & -0.027 & 0.023 & -0.300 & -1.142 & & \\
\hline $\mathrm{SW}(\mathrm{mm})$ & 0.004 & 0.018 & 0.072 & 0.244 & & \\
\hline $\mathrm{V}\left(\mathrm{mm}^{3}\right)$ & -0.001 & 0.005 & -0.028 & -0.163 & & \\
\hline PNR angle $\left({ }^{\circ}\right)$ & 0.004 & 0.004 & -0.114 & -0.733 & & \\
\hline Sex & 0.156 & 0.156 & -0.128 & -0.823 & & \\
\hline
\end{tabular}

Table 6. Impact in Inferior part of the maxillary sinus according to bizygomatic breadth. ${ }^{* *} \mathrm{p}<0.01$. P-value were obtained by Simple linear regression. 
et al. ${ }^{6}$. Kim et al. ${ }^{7}$ reported that the maxillary sinus and inferior wall are 3-D structures in humans and therefore cannot be characterized properly using 2-D imaging.

The measured CW, SW, and V were all larger in males on both the left and right sides in this study, whereas Kawakami et al. $^{3}$ reported that these three parameters were larger in females. This discrepancy is most likely due to differences between Koreans and westerners. Yoon et al. ${ }^{15}$ found that the maxillary sinus was larger in Koreans than in westerners. Therefore, the different results obtained in the present study compared to the study of Kawakami et al. could be attributed to the size difference in the inferior part of the maxillary sinus between Asians and westerners.

In our study, the PNR angle was larger in females than males on both sides, which is consistent with the findings of Kawakami et al. ${ }^{3}$. The PNR angle is an indicator of the detachment of the Schneiderian membrane during maxillary sinus floor augmentation. Chan et al. ${ }^{16}$ reported that a PNR angle of $<90^{\circ}$ can lead to perforation of the Schneiderian membrane. However, since the PNR angle was measured in 2-D in previous studies, we suggest that it would be difficult to measure the maximum angle. In our study, the PNR angle was measured accurately based on the maximum angle found in 3-D visualizations.

In this study, the inferior part of the maxillary sinus was compared in relation to the facial width based on the measured bizygomatic breadth distance. The result of the comparison between the males with $\geq 127$ and $<127$-mm bizygomatic breadths showed that for the inferior part of the maxillary sinus on the right side, the $<127$-mm group had larger NCF-F, CW, SW, and V than the $\geq 127-\mathrm{mm}$ group, whereas the PNR angle was larger in the $\geq 127-\mathrm{mm}$ group than in the $<127$ - $\mathrm{mm}$ group. Whether this result was in agreement with those of other studies could not be verified owing to the lack of previous studies. The result of the comparison between females with $\geq 127$ - and $<127$-mm bizygomatic breadths showed that for the inferior part of the maxillary sinus on the right side, the $\geq 127$-mm group had larger values of NCF-F, CW, SW, and PNR angle, whereas the $<127$ $\mathrm{mm}$ group had a larger $\mathrm{V}$ value. The comparison between males with $<127$-mm bizygomatic breadth and females with $\geq 127$-mm bizygomatic breadth for the inferior part of the maxillary sinus on the right and left sides showed larger PNR angles in females with $\geq 127$ - mm bizygomatic breadths than in males with $<127$-mm bizygomatic breadths, although the difference was not significant. Thus, the inferior part of the maxillary sinus varies in size according to facial width.

The results of the present study obtained from 3-D visualizations using CBCT data showed that the inferior part of the maxillary sinus was mostly larger in males than in females. In addition, it was found to be accurate in 3-D visualization data because the results of this study were generally similar, but statistically significant compared to previous studies. Therefore, care must be taken regarding the sex of the patient when maxillary sinus floor augmentation is performed in the future. In particular, because the PNR angle is greater in female patients than in male patients, precaution must be taken during the detachment of the Schneiderian membrane in male patients to prevent perforation. In addition, the inferior portion of the maxillary sinus showed different sizes according to the comparisons performed regarding the distance between bizygomatic breadths. Thus, when maxillary sinus floor augmentation is performed, the distance between the bizygomatic breadths should be taken into consideration. However, because the regression analysis demonstrated that only the distance between the bizygomatic breadths on the right side had a significant effect with regard to sex, a larger sample size in future studies may lead to significant results. The present study could be used as a reference for preventing complications while performing maxillary sinus floor augmentation as well as surgical procedures related to the inferior part of the maxillary sinus.

In this study, the data was not statistically significant because the number of male and female participants was not the same. In the future, it is expected that similar studies should be conducted with the same number of male and female participants so that further studies utilizing 3-D visualization will be able to yield useful fundamental data and guidelines for future research.

Received: 12 August 2020; Accepted: 12 November 2020

Published online: 03 December 2020

\section{References}

1. Pelinsari-Lana, J. et al. Anatomic variations and lesions of the maxillary sinus detected in cone beam computed tomography for dental implants. Clin. Oral Impl. Res. 23, 1398-1403 (2012).

2. Jeong, K. I., Kim, S. G., Oh, J. S. \& You, J. S. Implants displaced into the maxillary sinus: a systematic review. Implant Dent. 25, 547-551 (2016).

3. Kawakami, S., Botticelli, D., Nakajima, Y., Sakuma, S. \& Baba, S. Anatomical analyses for maxillary sinus floor augmentation with a lateral approach: a cone beam computed tomography study. Ann. Anat. 226, 29-34 (2019).

4. Pjetursson, B. E., Tan, W. C., Zwahlen, M. \& Lang, N. P. A systematic review of the success of sinus floor elevation and survival of implants inserted in combination with sinus floor elevation: part I: lateral approach. J. Clin. Periodontol. 35, 216-240 (2008).

5. Kawakami, S., Lang, N. P., Ferri, M., Alccayhuaman, K. A. A. \& Botticelli, D. Influence of the height of the antrostomy in sinus floor elevation assessed by cone beam computed tomography: a randomized clinical trial. Int. J. Max. Implant. 34, 223-232 (2019).

6. Cavalcanti, M. C. et al. Maxillary sinus floor pneumatization and alveolar ridge resorption after tooth loss: a cross-sectional study. Braz. Oral. Res. 32, e64 (2018).

7. Kim, H. J. et al. Personal-computer-based three-dimensional reconstruction and simulation of maxillary sinus. Surg. Radiol. Anat. 24, 392-398 (2002).

8. Tükel, H. C. \& Tatli, U. Risk factors and clinical outcomes of sinus membrane perforation during lateral window sinus lifting: analysis of 120 patients. Int. J. Max. Implant. 47, 1189-1194 (2018).

9. Danesh-Sani, S. A., Movahed, A., Elchaar, E. S., Chong-Chan, K. \& Amintavakoli, N. Radiographic evaluation of maxillary sinus lateral wall and posterior superior alveolar artery anatomy: a cone-beam computed tomographic study. Clin. Implant. Dent. Relat. Res. 19, 151-160 (2017).

10. Lim, E. L., Ngeow, W. C. \& Lim, D. The implications of different lateral wall thicknesses on surgical access to the maxillary sinus. Braz. Oral Res. 31, e97 (2017). 
11. Niu, L., Wang, J., Yu, H. \& Qiu, L. New classification of maxillary sinus contours and its relation to sinus floor elevation surgery. Clin. Implant. Dent. Relat. Res. 20, 493-500 (2018).

12. Kawakami, S. et al. Influence of the position of the antrostomy in sinus floor elevation assessed with cone-beam computed tomography: a randomized clinical trial. J. Investig. Clin. Dent. 9, e12362 (2018).

13. Kim, H. J. et al. Measurements of the zygomatic bones and morphology of the zygomaticofacial and zygomaticotemporal foramina in Korean. Korean J. Phys Anthrop. 10, 225-234 (1997).

14. Williams, P. L. et al. Gray's Anatomy. Embryology and Development. The Nervous System 38th edn, 1266-1274 (Churchill Livingstone, Edinburgh, 1995).

15. Yoon, H. R. et al. Morphometries of the maxillary sinus in Koreans. Korean J. Phys. Anthrop. 14, 127-135 (2001).

16. Chan, H. L., Monje, A., Suarez, F., Benavides, E. \& Wang, H. L. Palatonasal recess on medial wall of the maxillary sinus and clinical implications for sinus augmentation via lateral window approach. J. Periodontol. 84, 1087-1093 (2013).

17. Tallgren, A. The continuing reduction of the residual alveolar ridges in complete denture wearers: a mixed-longitudinal study covering 25 years. J. Prosthet. Dent. 27, 120-132 (1972).

18. Higuchi, K. W. \& Block, M. S. Current trends in implant reconstruction. J. Oral Maxillofac. Surg. 51, 7-19 (1993).

19. Mc-Gowan, D. A., Baxter, P. W. \& James, J. A. The Maxillary Sinus and Its Dental Implications 1st edn, 1-25 (Wright, London, 1993).

20. Ariji, Y., Ariji, E., Yoshiura, K. \& Kanda, S. Computed tomographic indices for maxillary sinus size in comparison with the sinus volume. Dentomaxillofac. Radiol. 25, 19-24 (1996).

21. Ariji, Y., Kuroki, T., Moriguchi, S., Ariji, E. \& Kanda, S. Age changes in the volume of the human maxillary sinus: a study using computed tomography. Dentomaxillofac. Radiol. 23, 163-168 (1994).

22. Khairnar, M. \& Gaur, V. Evidence of bone formation in the nasal floor around polished surface bi-cortical screw implants after indirect nasal lift in an atrophied maxilla: cone beam computed tomography-based case report. J. Indian Soc. Periodontal. 19, 236 (2015).

\section{Acknowledgements}

This work was supported by a National Research Foundation of Korea Grant funded by the Korean Government (NRF 2016R1D1A1B01008853).

\section{Author contributions}

J.-H.L. development, data collection, data analysis, manuscript writing. W.-J.H.: data collection, data analysis. J.-T.P.: development, data collection, data analysis, manuscript editing.

\section{Competing interests}

The authors declare no competing interests.

\section{Additional information}

Correspondence and requests for materials should be addressed to J.-T.P.

Reprints and permissions information is available at www.nature.com/reprints.

Publisher's note Springer Nature remains neutral with regard to jurisdictional claims in published maps and institutional affiliations.

(c) (i) Open Access This article is licensed under a Creative Commons Attribution 4.0 International

License, which permits use, sharing, adaptation, distribution and reproduction in any medium or format, as long as you give appropriate credit to the original author(s) and the source, provide a link to the Creative Commons licence, and indicate if changes were made. The images or other third party material in this article are included in the article's Creative Commons licence, unless indicated otherwise in a credit line to the material. If material is not included in the article's Creative Commons licence and your intended use is not permitted by statutory regulation or exceeds the permitted use, you will need to obtain permission directly from the copyright holder. To view a copy of this licence, visit http://creativecommons.org/licenses/by/4.0/.

(c) The Author(s) 2020 